\title{
Chapter 10 \\ Sustainability Improvements and Life Cycle Approaches in Industry Partnerships
}

\author{
Peter Saling
}

\begin{abstract}
Prioritizing sustainability as a key strategic focus and managing it similar to other parts of business such as marketing and sales, leading companies have been able to better identify and manage risks as well as enhance brand value and corporate reputation. With industry partnerships a holistic approach is possible. Common metrics, shared value chain data and joint sustainability management form the basis of a successful cooperation. Decision-making processes can be supported efficiently and influence the whole product system, thereby facilitating clear, measurable value creation throughout the supply chain. Industry partnerships with implementation of innovative business models are a key enabler for companies to realize more sustainable solutions.
\end{abstract}

Keywords Eco-efficiency analysis $\bullet$ Econsense network $\bullet$ Life cycle assessment $\bullet$ Life cycle management - PlasticsEurope - Sustainable solution steering • Sustainability

\section{Introduction}

Awareness of sustainability in business decisions has an increasing importance for different stakeholders. To develop more sustainable solutions which meet society's needs is a key challenge in industries along the whole value chain.

There is a growing awareness in the financial market that a company geared towards sustainable development in order to outperform peers over the long-term while minimizing risks.

P. Saling $(\bowtie)$

BASF SE, Sustainability Strategy, Ludwigshafen, Germany

e-mail: peter.saling@basf.com 


\section{Industry and Associations Initiatives}

\subsection{Together for Sustainability (TfS)}

Several initiatives of industries and associations have been founded with the goal, to implement sustainability principles in supply chains and to improve product applications. There are well defined networks exchanging general information but as well industrial collaboration networks exchanging and offering LCI information to calculate complete LCA studies.

A good example for initiating a general information platform to improve sustainability is a new initiative of the chemical industry, the "Together for Sustainability" platform, where chemical companies work together for improving sustainability in their supply chain. As multinational leading companies, chemical companies strive for a sustainable development and support the principles of the United Nations Global Compact and Responsible Care. The companies take responsibility for their own operations and in the sphere of their influence for our supply chains to support adherence to existing regulations and to respond to the needs and expectations of consumers and society. To use resources more efficiently and reduce the bureaucratic burden for suppliers, the participating companies share supplier sustainability assessment and audit data.

Within the TfS assessment as well as audit, the supplier's sustainability performance is verified against a pre-defined set of audit criteria. These topics have been defined by TfS and are tailored to the requirements of the chemical industry.

Benefits for the companies but as well for other players in the supply chain are seen in avoiding double audits and assessments, improvement and assurance of quality of assessment and audit results. Sharing of assessment and audit results with multiple customers on one platform, high quality through selected and qualified partners are additional benefits. Engaging with customers on sustainability requirements and challenges for building up long-term business relationships will be a positive outcome as well as lowering risks in relation to sustainability requirements. Knowing sustainability performance allows to improve performance (TfS 2012, 2015). This can be achieved additionally by calculating facts about products and their precursors with an LCA approach to generate detailed information.

One example for a cross sector initiative is the econsense network. The goal of this initiative is an open dialogue, the members of econsense strive to further advance the implementation of economic, social and ecological objectives, with the awareness that business with strengths in innovation and investment also assumes certain responsibility for the success of sustainable development. At the same time, companies can only discern their corporate social responsibility when supportive and reliable political framework conditions offer them a sound environment. The objectives of econsense are:

- To pool corporate activities on sustainability topics, such as climate protection and demographic change, and to jointly further develop these projects

- To actively shape the political and social discourse

- To credibly communicate the solution competence of the economy 
- To strengthen the open dialogue between political and social groups

- To highlight the possibilities and limitations of corporate responsibility

- To promote sustainability concepts and CSR in the business community and raise awareness of policymakers for framework conditions that promote innovation and competitiveness (econsense 2014)

\subsection{Life Cycle Inventory Data Platforms of Associations}

Associations provide more and more data for LCA practitioners. Single LCI information in a format that can easily be used and introduced to common LCA software systems and is very helpful to generate complete LCA studies based on average figures of the relevant industries.

PlasticsEurope (2011) promotes the use of life cycle thinking (LCT) to improve understanding about product benefits and to take more informed decisions. As a scientific method, life cycle assessment (LCA) is a technique to analyze the potential environmental impacts associated with a product, process or service. It involves:

- Compiling an inventory of energy and material inputs and environmental releases

- Assessing the potential environmental impacts associated with identified inputs and releases

- Calculating performance indicators to inform decisions

PlasticsEurope was the first industry organization to assemble and publish detailed environmental data on the processes operated by its member companies. The first Eco-profile reports were published in 1993. Since then, more reports have been added and continuously updated, so that there are now more than 70 Ecoprofile reports freely available. In 2006, a complementary Environmental Product Declaration (EPD) programme was started. Eco-profiles and EPDs cover high volumes, bulk polymers, some of the more widely used engineering plastics and several common plastics conversion processes (Boustead 1993). Widely acknowledged among life cycle practitioners and other stakeholders worldwide as representative datasets, they have been included in various commercial life cycle databases as well as in the publicly available European Reference Life Cycle Data System (ELCD).

PlasticsEurope has clear objectives when compiling the Eco-profile reports, representing European production averages:

- The first is to place scientifically sound data in the public domain for use in product life-cycle studies, without compromising the confidentiality of detailed process data of the individual companies.

- The second is to encourage environmental improvements in production processes through benchmarking against a European industry average.

- The third key factor is that, given the large contribution of upstream effects to the Eco-profile of a polymer and in view of the distribution of input materials, such as ethylene or naphtha via the European pipeline network, industry averages are the most robust representation of polymer production systems. 
Since the first Eco-profile reports were published, the LCA methodology, standardization and practice have undergone substantial changes. New concepts, such as EPD, Carbon Footprint or Product Environmental Footprint (PEF) have emerged. Downstream industries like the building and construction sector have their own standards and data needs. Hence, Eco-profiles need to change in response to best practices and stakeholder needs. To this end, PlasticsEurope periodically seeks stakeholder input on the Eco-profile methodology. Furthermore, in view of the need for globally harmonized practices and comparable results, PlasticsEurope welcomes and actively invites liaisons with other regional federations. As a contribution towards shared best practices, the Eco-profile methodology aligns with other material- or sector-specific standards.

\subsection{Steering Product Portfolio to Foster Sustainable Solutions}

The ambition to create sustainable products and services is being driven by a number of compelling business factors. New laws and standards regarding carbon emissions and other sustainability topics are being implemented all over the world. At the same time, there is growing market uncertainty about the cost of raw materials and the availability of natural resources. Finally, the end consumers are evolving their expectations about the goods and services they purchase. Increasingly, they are holding brand owners and companies to a higher account in terms of materials that go into consumer products and the way those products are made.

BASF started and will continuously analyze the complete portfolio from the viewpoint of the sustainability needs of their customers. Therefore BASF developed the evaluation process "Sustainable Solution Steering" that allows to gain enhanced internal transparency and consistency on the sustainable development performance in all areas of the business globally (BASF 2015). The process also acts as an early warning system that can identify where solutions are facing sustainability obstacles. It also helps to identify sustainability benefits for the company, customers, society and the environment. In addition, Sustainable Solution Steering provides the business units with the information they need to communicate opportunities for sustainable solutions. This insight can be used to differentiate in the specific markets, enter into dialog with customers about their sustainability needs and hence generate new business opportunities.

First a qualifier check is conducted, where each solution is evaluated based on companies and the value-chain-specific performance for economic, environmental and social criteria. After that, the solutions are ranked according to their sustainability performance in the respective application and clustered into one of the following four categories:

- Accelerator: A solution with a substantial sustainability contribution in the value chain 
- Performer: A solution that meets the basic sustainability standards in the marketplace

- Transitioner: A solution for which a specific sustainability issue is actively addressed

- Challenged: A solution with a significant sustainability concern identified and for which an action plan is under development

LCA information or as well eco-efficiency analysis results can be used to support this evaluation process.

Ultimately, Sustainable Solution Steering will benefit customers by delivering new business opportunities through innovative solutions as well as providing support on their own sustainability needs. It is a life cycle management process that can be applied to other industries as well (Kicherer and Voeste 2014).

\section{Examples of Assessments and Applications}

\subsection{Using Plastics Europe LCI Information}

In order to produce plastic products, energy resources are consumed. Currently such energy resources are almost entirely obtained from non-renewable sources, and by using them, greenhouse gas (GHG) emissions are produced. Nevertheless, even more energy would be consumed and more GHG emissions emitted, if plastic products are to be substituted by alternative materials. This was established in a study by (Pilz et al. 2005).

The study generally follows an "80/20-approach", meaning that the authors aim to cover $80 \%$ of influences with $20 \%$ of effort that would be required for a more comprehensive study. As a result, a high degree of reliability was ensured for the general magnitude of the overall results, but not for every specific figure in the case studies investigated, where - based on the "80/20-approach" - many (reasonable) assumptions had to be made where data were not easily available.

Calculation of life cycle energy and GHG emission balances: Data for the production phase of plastic products were mostly taken from the "Ecoprofiles" as published by PlasticsEurope. Production data of alternative materials was taken from the database ecoinvent (2007) or comparable sources. In the use phase the calculation covers issues where plastic products have a different impact on energy and GHG emissions compared to alternative products. The effects considered are mainly fuel consumption for transportation, prevented food losses, differences in thermal insulation properties, and fuel savings due to the lower mass of plastic automotive parts.

For example, substituting plastics in the case studies throughout Europe $(\mathrm{EU} 27+2)$ in 2007 would increase the life cycle energy consumption by around 2.140 million GJ per year and the GHG emissions would increase by $110 \mathrm{Mt} \mathrm{CO}_{2}$ equivalents per year. 
The energy savings that can be attributed to the use of plastics varies significantly according to the application area, with packaging being by far the most important. A conservative estimate of the impact of the total plastics market has been made by extrapolation using only half of the energy savings and GHG emission reductions of the quoted examples.

The results show that the total life cycle energy needed to produce, use and recover plastic products in Europe (EU27+2) is 4.300 million GJ/a and the total life cycle GHG emissions are $200 \mathrm{Mt} / \mathrm{a} .2$ Furthermore it can be concluded that substitution of plastic products by other materials wherever possible would need around $57 \%$ (1.500-3.300 million GJ/a) more energy than currently used in the total life cycle of all plastic products today. In the same way, substitution of plastic products up to the theoretical maximum would cause $78-170$ Mt or about $61 \%$ more GHG emissions than the total life cycle of all plastic products today.

In other words, the plastic products on the market today have enabled energy savings of 2.400 million GJ per year, equivalent to 53 million tonnes of crude oil carried by 205 very large crude oil tankers.

The GHG emissions saved (124 Mt per year) are equivalent to the total $\mathrm{CO}_{2}$ emissions of Belgium in the year 2000 (UNFCCC 2009) and are also equivalent to $39 \%$ of the EU15 Kyoto target regarding the reduction of GHG emissions (Pilz et al. 2010).

\subsection{Evaluating Product Sustainability, a Contribution from CEFIC}

Industry has already made significant achievements in sustainability, driving safe, environmentally sound operations through its Responsible Care ${ }^{\circledR}$ scheme and corporate social responsibility activities. These efforts were started well before the United Nations' Rio Declaration in 1992 and have become ever more important since.

Today, emerging regulatory and social trends around sustainability create both pressures and opportunities for chemical companies at global and EU levels. Legislative requirements, stakeholder expectations and companies' own business and Responsible Care strategies are driving the development of more sustainable chemical products and supply chains.

Clear trends are already surfacing:

- The introduction of REACH creates new pressures on specific substances.

- The emergence of eco-design, Green Public Procurement (GPP), Ecolabel criteria and waste prevention schemes is creating demand for more sustainable products.

- Rising consumer interest in sustainable goods is incentivising retailers to develop sustainability measures for their suppliers. 
The move towards sustainable products will take many years to progress through legislative and business processes. During this time, retailers, consumers and nongovernmental organizations (NGOs) will continue to call for transparency and clear statements about the constituents of the goods they purchase.

The Eco2chem project for eco-efficiency measurement set up at sector level in Belgium and actively supported by local authorities and several research organizations, aims to select the best-fit eco-efficiency measurement methods applicable to chemical processes and products. The main outcome is SUSCHEMCompass, a web-based tool to help companies, especially SMEs, select the eco-efficiency measurement method best suited to their specific needs.

The tool focuses on measurement methods for the economic and environmental aspects at company level and/or project level, but may be extended to social aspects in a follow-up project. A variety of methods have been identified, ranging from quick scans to thorough life cycle analysis and from freely available tools to proprietary tools. For each method, the web-based tool includes an information sheet summarizing the history and scope of the method, and what it can and cannot measure. The tool can be used by all interested parties free of charge (CEFIC 2012).

\subsection{Sustainability Improvements Support with Eco-Efficiency Studies: Pavement Preservation Technology for Asphalt Roads}

The society depends on roads as a vital component of their national economies. Ensuring that these roads are safe, long-lasting and cost effectively installed and maintained is thus essential to the sustainability of the transportation network. Pavement preservation is the systematic scheduling of nonstructural maintenance applications to protect engineered road pavements and extend their service life. This helps promote better road conditions, increases safe driving by minimizing surface deterioration and the potential for structural failure and is a more efficient use of tax payer money. The challenge facing many government agencies and key material specifiers is how can they decide which pavement preservation technologies and materials are the most eco-efficient? On what basis should they make their comparison and what metrics truly define the sustainability of road construction materials? BASF in collaboration with a key customer, Vance Brothers, utilized the ecoefficiency analysis to compare the relative eco-efficiencies of two of the more prevalent pavement preservation technologies for urban roads in the United States. The life cycle environmental and economic impacts of a polymer modified asphalt emulsion based micro-surfacing technology were compared to a two-inch polymermodified hot mix overlay. The analysis was based on the environmental and economic impacts required to maintain a one-mile stretch of a $12 \mathrm{ft}$ lane of urban road using best engineering practices for a 40 year lifetime. The question was whether it was more sustainable to install a more durable layer (hot mix overlay also 
known as Mill and Fill) that contained $10 \%$ recycled materials but required overall more materials and extensive road work or to utilize a less cost and resource intensive maintenance technology like micro-surfacing more frequently (due to its shorter lifespan) in order to achieve the same desired road performance. The ecoefficiency study along the whole supply chain with a cradle to grave approach showed that micro-surfacing consumes about $40 \%$ less primary energy and resources than hot mix overlays over the 40 year life cycle of the road. Hot mix overlays scored higher due to higher bitumen consumption, hotter production and application temperatures as well as increased fuel requirements for transporting larger amounts of materials to and from the job site.

Having detailed results depicting how the individual system components contribute to the overall impact category is essential for informed decision making. Of particular interest was the discovery of the significant environmental impact the road markings had over the life cycle for micro-surfacing. Thus to further improve the overall eco-efficiency of micro-surfacing it may be necessary to look at optimizing other aspects of the system components which make up the overall technology.

By using more sustainable products and solutions, it clearly was shown that the micro-surfacing technology has a significantly reduced environmental fingerprint. These benefits can be directly attributed to its more efficient use of resources, its lower energy consumption as well as lower overall emissions to the environment. By combining its preferred environmental profile with its reduced life cycle cost ( $25 \%$ less than hot mix overlay), clearly places micro-surfacing as a more ecoefficient material for the base case analysis.

With any rigorous analysis that involves copious amounts of data, it is essential that the results are presented and communicated in a way that facilitates clear understanding as well as helps bring into context the significance of the findings. The eco-efficiency methodology by BASF through the use of the environmental fingerprint and portfolio is well suited to distilling vast amounts of data and presenting it in a concise, balanced format (Saling et al. 2002, 2005; Landsiedel and Saling 2002).

As many important stakeholders of LCA or eco-efficiency studies are not as well versed in many of the common units of measurements (e.g. grams $\mathrm{SO}_{2}$ equivalents for assessing acidification potential or mega-joules for energy consumption) they are sometimes not able to adequately assess the relative significance of the measured impacts. Thus communicating the results in more commonly understood terms or equivalencies is an essential aspect to effectively communicating the results and ultimately facilitating strategic review and decision making.

Just considering the context of the micro-surfacing study which was for only a single mile stretch of urban road over 40 years, the advantages of micro-surfacing over hot mix overlay could additionally be expressed in more commonly understood equivalencies such as:

- Approximately $540,000 \mathrm{~kg}$ less material required

- $34 \mathrm{t}$ less material sent to land fill

- Energy efficiency (EIA 2005): 
- Savings equivalent to the annual consumption of energy in 110 US homes

- Over 42,000 L less oil consumed per every lane-mile

- Smaller carbon footprint (EPA 2015):

- Reduction equivalent to taking over 20 cars off the road

- Carbon sequestered annually by over 8 ha of pine forest

Through the use of eco-efficiency and the communication of results using common equivalencies, state agencies will be able to make more informed and strategic decisions related to promoting the sustainability of road constructions (Uhlman and Saling 2010).

\section{Conclusions}

The life cycle approach for partnerships of companies along supply chains enables different industries the identification of hotspots, improvements of their products and applications and finally the marketing of more sustainable solutions in the market.

Through collaboration toward common goals, business can address some of the critical environmental and social problems the world faces while strengthening their own resilience to global challenges. Different types of business solutions can be generated. Main conditions for them are to be impactful, measurable, scalable, replicable and beyond business-as-usual.

Scalable means that they can have a meaningful impact on the world.

Replicable enables them to be applied by many companies, in multiple sectors, regions and countries.

Measurable is important to know how they are making a difference. Beyond business as usual businesses and governments begin to work - and collaborate - differently.

In sum, the initiatives are good for business, so they have a commercial logic that contributes to the broader good and to the bottom line (WBCSD 2015, Vision 2020).

Action2020 is the WBCSD platform for sustainability in action. It is the roadmap for how business can positively influence environmental and social trends while strengthening their own resilience to issues like climate change, demographic dynamics and skills shortages. Based on the latest scientific consensus, action 2020 sets an agenda for business to take action on sustainable development to 2020 and beyond.

LCA tools, eco-efficiency analysis and other LCM tools and approaches can support the basic needs for the development towards more sustainable solutions in the market with scientific sound, detailed and meaningful information quite efficiently and will be used more intensively in the future. The collaboration between different stakeholders in the market will help to make significant improvements and foster more sustainable solutions. Analytical tools as LCA can support decision-making, 
visualization and marketing as well as the management of products in the value chains.

LCM tools enable companies to drive innovative product development focused on bringing more sustainable products to the market place. The tools and methods behind them clearly identify the factors whose optimization will directly translate into improvements in the sustainability profile, even during the early stages of product development. It facilitates clear understanding of trade-offs and helps in preventing inadvertently shifting environmental impacts from one area to another or between the economic and environmental pillars. By measuring the impacts on a system level and including a comprehensive approach to environmental impact assessment, it also safeguards against potentially reaching false conclusions that could result when only single metrics were considered.

Life cycle management tools applied in the collaboration and partnerships of companies and industries is also an effective market communication tool. Since the entire life cycle of a product is analyzed, the effects on customers along the supply chain can be quantified and evaluated and thus a more strategic value proposition can be developed. Communication can also go beyond direct customers with the results being used to support engagement and education amongst government agencies, regulatory bodies and NGOs.

Open Access This chapter is distributed under the terms of the Creative Commons Attribution Noncommercial License, which permits any noncommercial use, distribution, and reproduction in any medium, provided the original author(s) and source are credited.

\section{References}

BASF (2015) Sustainable investments. https://www.basf.com/en/company/investor-relations/ sustainable-investments.html

Boustead I (1993) Eco-profiles of the European plastics industry. Report 3: Polyethylene and polypropylene. Report to The European Centre for Plastics in the Environment (PWMI) (later Association of Plastic Manufacturers in Europe (APMI)), Brussels May 1993

CEFIC (2012) Sustainability of products - what it's all about. http://www.cefic.org/Documents/ IndustrySupport/RC\%20tools\%20for\%20SMEs/Document\%20Tool\%20Box/Sutainability_ of_products_What_its_all_about.pdf

econsense (2014) http://www.econsense.de/sites/all/files/Basisflyer_E_2014\%20neu.pdf

EIA (2005) Energy Information Administration (EIA). Residential energy consumption survey. Energy consumption and expenditures. Tables: www.eia.doe.gov

EPA (2015) Greenhouse gas equivalencies calculator. United States Environmental Protection Agency. http://www.epa.gov/cleanenergy/energy-resources/calculator.html

Kicherer A, Voeste D (2014) Sustainable solution steering, our approach to support our customers. https://www.basf.com/documents/corp/en/sustainability/management-and-instruments/ sustainable-solution-steering/BASF_Booklet_Sustainable_Solution_Steering.pdf

Landsiedel R, Saling P (2002) Assessment of toxicological risks for life cycle assessment and ecoefficiency analysis. Int J Life Cycle Assess 7(5):261-268

Pilz H, Schweighofer J, Kletzer E (2005) The contribution of plastic products to resource efficiency. PlasticsEurope - Association of Plastics Manufacturers, Brussels 
Pilz H, Brandt B, Fehringer R (2010) The impact of plastics on life cycle energy consumption and greenhouse gas emissions in Europe, Summary report June

PlasticsEurope (2011) Eco-profiles and environmental declarations - LCI methodology and PCR for uncompounded polymer resins and reactive polymer precursor (version 2.0, April 2011). www.plasticseurope.org

Saling P, Kicherer A, Dittrich-Kraemer B, Wittlinger R, Zombik W, Schmidt I, Schrott W, Schmidt S (2002) Eco-efficiency analysis by BASF: the method. Int J Life Cycle Assess 7(4):203

Saling P, Maisch R, Silvani M, König N (2005) Assessing the environmental-hazard potential for life cycle assessment, eco-efficiency and SEEbalance. Int J Life Cycle Assess 10(5):364-371

TfS (2012) Brochure. http://www.tfs-initiative.com/download/TfS_Brochure_en.pdf

TfS (2015) Overview. http://www.tfs-initiative.com/benefits_and_criteria.html

Uhlman BW, Saling P (2010) Measuring and communicating sustainability through eco-efficiency analysis. Chem Eng Prog, CEPE 106(12):17-26

UNFCCC (2009) United Nations Framework Convention on Climate Change. In: UNFCCC conference, Copenhagen, Dec 2009

WBCSD (2015) Action 2020 overview. http://www.wbcsd.org/Pages/EDocument/ EDocumentDetails.aspx $?$ ID $=16154 \&$ NoSearchContextKey=true 